\title{
Utility of the Hand-Drawn Spiral as a Tool in Clinical-Epidemiological Research on Essential Tremor: Data from Four Essential Tremor Cohorts
}

\author{
Elan D. Louis \\ Department of Neurology, Yale School of Medicine, Yale University, New Haven, Conn., USA
}

\section{Key Words}

Essential tremor · Epidemiology · Clinical · Screening · Validity

\begin{abstract}
Background: In descriptive epidemiological studies, investigators must screen large numbers of individuals. How one best screens populations for essential tremor (ET); however, remains an open question. The collection of a standardized writing sample (e.g., a hand-drawn spiral) is a method with many practical advantages, yet there are virtually no data on the validity of this particular method. Methods: Four handdrawn spirals (2 right, 2 left) were collected from 831 ET cases across four distinct study settings (population-based study, family study, environmental epidemiological study, brain repository) and, in two of these studies, from 697 controls. Spirals were rated (range $0-3$ ) by a senior movement disorder neurologist. These 1,528 participants also underwent a detailed neurological examination, and total tremor scores (range 0-36) and ET diagnoses were assigned by the neurologist. Results: The proportion of cases with handdrawn spiral ratings $\geq 1.5$ in either arm ranged from 78.8$97.0 \%$; only $4.7 \%$ of controls had spirals with tremor of that severity. The hand-drawn spiral rating was highly correlated with the total tremor score $(r=0.65-0.73, p<0.001)$. Conclu-
\end{abstract}

sions: The hand-drawn spiral is a sensitive and specific method of screening for ET. Furthermore, it serves as a valid measure of overall tremor severity.

(c) 2015 S. Karger AG, Basel

\section{Introduction}

In epidemiological studies, and especially prevalence studies, it is often important to screen large numbers of individuals using methods that are easily introduced into a test battery, rapid to administer, and of diagnostic validity. Among the numerous neurological disorders, essential tremor (ET) is one of the most common [1-4]. Yet how one best screens populations for ET remains an open question. The collection of a standardized writing sample (e.g., a hand-drawn spiral) is one method that is commonly employed in clinical settings to assess tremor severity $[5,6]$ and it has recently been adopted into some epidemiological studies [7]. The method has many practical advantages. It is easy to obtain the spirals and their execution requires little time. Indeed, hand-drawn spirals

Statistical Analyses: The statistical analyses were conducted by Dr. Louis.

\section{KARGER 125}

(C) 2015 S. Karger AG, Basel

0251-5350/15/0441-0045\$39.50/0
Elan D. Louis

Yale School of Medicine, Department of Neurology

LCI 710, 15 York Street, PO Box 208018

New Haven, CT 06520-8018 (USA)

E-Mail elan.louis@yale.edu 
may even be collected from participants by email, facsimile, postal service and other methods, none of which require investigators to travel, thereby saving both time and resources when screening large numbers of people. The question naturally arises then as to the validity of the method. Surprisingly, there are virtually no published data to address this methodological issue.

The primary aims of this study were to assess how well the hand-drawn spiral performs (1) as a screening tool for ET and (2) as a summary measure of tremor severity (i.e., how well does it correlate with the total tremor score)? The knowledge is expected to guide future epidemiological investigations of this common disorder.

$\mathrm{ET}$ is a disease that can range considerably in terms of its severity, and cases in the population tend to have milder tremor than those ascertained from clinics $[8,9]$. To address the study aims across a broad range of settings, these analyses utilized four distinct patient samples: a population-based study in northern Manhattan [10], a study of the environmental epidemiology of ET [11], a family study [12], and a brain repository [13]; in total, 831 ET cases were sampled in these four datasets. Two of these studies also included the enrollment of control participants, with a combined sample of 697 controls.

\section{Methods}

In two of the four studies, control participants were also available. Participants signed written informed consent approved by the Columbia University Medical Center (CUMC) institutional ethics board. In each study, participants underwent a demographic and medical history and a videotaped tremor examination during which four spirals were hand-drawn (two with dominant hand and two with non-dominant hand).

\section{Population-Based Study in Northern Manhattan}

The Washington Heights-Inwood Genetic Study of Essential Tremor (WHIGET) was a family study of ET in the Washington Heights-Inwood community in northern Manhattan, New York. Enrollment was completed in 2000. Enrollees included $106 \mathrm{ET}$ cases (59 probands with ET, 33 of their relatives with ET, and 14 affected relatives of control probands). Enrollees also included probands without ET and their unaffected relatives $(n=268)$. The design of this population-based study has been described in detail $[10,14,15]$.

\section{Study of the Environmental Epidemiology of ET}

388 ET cases were enrolled in a study of the environmental epidemiology of ET; enrollment began in 2000 and ended in 2009 [11]. Cases were derived from two main sources: the Neurological Institute of New York at CUMC and the membership of the International Essential Tremor Foundation (IETF) who lived in the New York metropolitan region. As this was a case-control study, 429 controls (i.e., persons without ET) from the same source population were also enrolled.

\section{Family Study of Essential Tremor}

ET probands and their first-and second-degree relatives were enrolled in the Family Study of Essential Tremor (FASET), a genetics study of ET [16, 17]. Participants lived throughout the United States. Based upon a telephone interview with the proband, relatives with ET were identified. The final sample comprised 207 individuals (i.e., 52 probands and 155 relatives), including $160 \mathrm{ET}$ cases, 28 borderline ET cases, and 19 normal [16].

\section{Essential Tremor Centralized Brain Repository}

The Essential Tremor Centralized Brain Repository (ETCBR) is a centralized repository for the prospective collection and study of ET brains $[13,18]$. ET cases throughout the United States were recruited as future brain donors through the IETF and other sources. These ET cases were highly selected because many were ascertained through a disease-specific organization and because they self-referred to the brain repository as future brain donors $[13,14]$. The large majority of these cases have seen physicians who diagnosed ET [18]. Nine of these were also enrolled in the study of environmental epidemiology of ET.

\section{Medical History, Videotaped Tremor Examination and}

Diagnostic Confirmation

In each study, the medical history included questions on demographics, medications, and features of tremor, including the question, 'Does your hand usually tremor when you hold a pen or write your name?' The videotaped tremor examination included assessments of postural and kinetic tremors (arms) and head (neck), voice, and jaw tremors. The videotaped examination included one test for postural tremor and five tests for kinetic tremor (e.g., pouring, using spoon, drinking) performed with each arm (12 tests total). The hand-drawn spirals were executed in an identical manner in each study: spirals were drawn freely on a blank, standard $8.5 \times 11$-inch sheet of paper using a ballpoint pen while the participant was seated at a table. The paper was centered at right angles (horizontally) directly in front of them and held down by their other hand. Participants started at the center of the page, without lifting their pen. They were asked not to rest their writing hand, wrist or arm on the table while drawing.

In each study, a neurologist specializing in movement disorders (E.D.L.) used a reliable [19] and valid [20] clinical rating scale, the WHIGET Tremor Rating Scale, to rate postural and kinetic tremor during each test, including the four hand-drawn spirals: 0 (none), 1 (mild), 2 (moderate), 3 (severe) (see examples in Louis et al. [7]). In three of the four studies, additional ratings of 0.5 and 1.5 were added for greater precision, with the rating 1.5 indicating tremor that was of moderate amplitude and clearly oscillatory but only sometimes of moderate amplitude (e.g., see fig. 3 in Louis et al. [7]). Each participant thus had four hand-drawn spirals ratings (range for each $=0-3)$ and a total tremor score $($ range $=0-36)$, which is an assessment of postural and kinetic tremor in the arms during 12 tests [11].

In each study, the enrollment diagnosis of ET was reassessed (E.D.L.) based on the history and videotaped examination. All ET cases included in these analyses met published, reliable criteria for ET (moderate or greater amplitude kinetic tremor of the arms (rating $\geq 2$ ) during at least three tasks or head tremor, in the absence of Parkinson's disease, dystonia or another cause) $[15,19$, 21]. 
Table 1. Demographic and clinical features of participants in four study samples

\begin{tabular}{|c|c|c|c|c|c|c|}
\hline & \multicolumn{2}{|c|}{$\begin{array}{l}\text { Population-based study } \\
\text { in northern Manhattan }\end{array}$} & \multicolumn{2}{|c|}{$\begin{array}{l}\text { Study of the environmental } \\
\text { epidemiology of ET }\end{array}$} & \multirow{2}{*}{$\begin{array}{l}\text { Family study } \\
\text { of essential } \\
\text { tremor, cases }\end{array}$} & \multirow{2}{*}{$\begin{array}{l}\text { Essential tremor } \\
\text { centralized brain } \\
\text { repository, cases }\end{array}$} \\
\hline & cases & controls & cases & controls & & \\
\hline $\mathrm{n}$ & 106 & 268 & 388 & 429 & 160 & 177 \\
\hline Age, years & $69.8 \pm 18.4$ & $51.3 \pm 22.7$ & $67.4 \pm 15.3$ & $67.9 \pm 12.3$ & $60.0 \pm 18.0$ & $83.7 \pm 5.8$ \\
\hline Female gender & $63(59.4)$ & $169(63.1)$ & $201(51.8)$ & $255(59.4)$ & $82(51.3)$ & $108(61.0)$ \\
\hline Tremor duration, years & $15.4 \pm 18.8$ & NAp & $22.8 \pm 18.7$ & NAp & $32.8 \pm 19.3$ & $41.3 \pm 22.3$ \\
\hline Age of tremor onset, years & $56.7 \pm 25.6$ & NAp & $44.7 \pm 22.5$ & NAp & $27.0 \pm 17.8$ & $42.4 \pm 22.9$ \\
\hline Currently taking medication for tremor & $5(4.7)$ & $0(0.0)$ & $209(53.9)$ & $0(0.0)$ & $79(49.4)$ & $115(65.0)$ \\
\hline Family history of ET & $106(100)$ & NAp & $119(30.7)$ & NAp & $160(100)$ & $48(27.1)$ \\
\hline Voice tremor on examination & $16(15.1)$ & $0(0.0)$ & $118(30.4)$ & $0(0.0)$ & $26(16.3)$ & $71(40.1)$ \\
\hline Head tremor on examination & $19(17.9)$ & $0(0.0)$ & $143(36.9)$ & $0(0.0)$ & $60(37.5)$ & $92(52.0)$ \\
\hline
\end{tabular}

All values are means \pm standard deviations or numbers (percentages).

In the population-based study in northern Manhattan and the study of the environmental epidemiology of ET, the data in the upper box is from cases and the data in the lower box is from controls. NAv = Not available; NAp = not applicable.

\section{Statistical Analyses}

Data on each of the four case samples were analyzed separately in SPSS (Version 22). Sensitivity was the proportion of ET cases whose hand-drawn spiral rating was above a specified severity cutoff (e.g., a tremor rating $\geq 1.5$ ). Specificity was the proportion of controls whose hand-drawn spiral rating was below a specified severity cut-off. Spiral ratings were not normally distributed; therefore, to assess the association between spiral ratings and total tremor score, a non-parametric approach (Spearman's correlations) was used.

\section{Results}

There were four ET case samples, which by design differed from one another, and which sampled a broad range of ET cases. On one end of the spectrum was the populationbased sample, in which tremor severity and duration were the least, and on the other end of the spectrum was the brain repository, in which tremor severity and duration were the greatest. Participant characteristics are shown (table 1).

The proportion of cases with hand-drawn spiral ratings $\geq 2$ was lowest in the population-based study, highest in the brain repository, and intermediate in the other two studies (table 2).

The proportion of cases with hand-drawn spiral ratings $\geq 2$ in the dominant arm ranged from as low as $29.9 \%$ (population-based study) to as high as $80.1 \%$ (brain repository); by contrast, $0.0-3.0 \%$ of controls had spirals with tremor of that severity (table 2 ). The proportion of cases with a hand-drawn spiral rating $\geq 2$ in either arm ranged from $50.5-89.1 \%$; by contrast, $0.0-6.7 \%$ of controls had spirals with tremor of that severity in either arm (table 2). The proportion of cases with hand-drawn spiral ratings $\geq 2$ in both arms ranged from as low as $25.5 \%$ (populationbased study) to as high as $69.1 \%$ (brain repository); by contrast, $0.0-0.4 \%$ of controls had spirals with tremor of that severity in both arms (table 2). Lowering the severity cutoff improved the results. For example, the proportion of cases with hand-drawn spiral ratings $\geq 1.5$ in either arm reached values of 93.6 and $97.0 \%$ in two of the ET case samples, compared with $4.7 \%$ of controls (table 2 ).

A sub-analysis was performed that excluded ET cases who were taking ET medication. In the largest sample (i.e., the study of environmental epidemiology), handdrawn spiral data were available on 178 of such cases. The proportion of these cases with hand-drawn spiral ratings $\geq 1.5$ in either arm was $120 / 178(67.4 \%)$; this value was $11.4 \%$ lower than that obtained in the entire sample of 386 cases $(78.8 \%)$. These data suggest that un-medicated ET cases have tremor that is slightly less severe, and that the sensitivity of the hand-drawn spiral is slightly diminished as a result.

The hand-drawn spiral performed well as a measure of tremor that was representative of the total tremor score. In cases, the hand-drawn spiral (dominant arm) correlated highly with the total tremor score (Spearman's $r=$ $0.66-0.70, \mathrm{p}<0.001)$. In controls, the same correlation remained highly significant, although was slightly less robust (Spearman's $\mathrm{r}=0.45-0.52, \mathrm{p}<0.001$ ). 
Table 2. Severity of tremor in hand-drawn spirals in four ET case samples

\begin{tabular}{|c|c|c|c|c|}
\hline & $\begin{array}{l}\text { Population-based } \\
\text { study in northern } \\
\text { Manhattan }\end{array}$ & $\begin{array}{l}\text { Study of the } \\
\text { environmental } \\
\text { epidemiology of ET }\end{array}$ & $\begin{array}{l}\text { Family study of } \\
\text { essential tremor }\end{array}$ & $\begin{array}{l}\text { Essential tremor } \\
\text { centralized brain } \\
\text { repository }\end{array}$ \\
\hline $\mathrm{n}$ & 106 & 388 & 160 & 177 \\
\hline \multicolumn{5}{|l|}{ Hand-drawn spiral rating } \\
\hline$\geq 2$ in dominant $\operatorname{arm}^{1}$ & $37 / 106(29.9)$ & $151 / 386(39.1)$ & $70 / 159(44.0)$ & $133 / 166(80.1)$ \\
\hline$\geq 2$ in either $\operatorname{arm}^{1}$ & $74 / 106(69.8)$ & $195 / 386(50.5)$ & $94 / 156(60.3)$ & $147 / 165(89.1)$ \\
\hline$\geq 2$ in both arms $^{1}$ & $27 / 106(25.5)$ & $107 / 386(27.7)$ & $55 / 156(35.3)$ & $114 / 165(69.1)$ \\
\hline$\geq 1.5$ in dominant $\operatorname{arm}^{1}$ & $\mathrm{NAv}^{2}$ & $234 / 386(60.6)$ & $128 / 159(80.5)$ & $154 / 166(92.8)$ \\
\hline$\geq 1.5$ in either $\operatorname{arm}^{1}$ & $\mathrm{NAv}^{2}$ & $304 / 386(78.8)$ & $146 / 156(93.6)$ & $160 / 165(97.0)$ \\
\hline$\geq 1.5$ in both arms ${ }^{1}$ & $\mathrm{NAv}^{2}$ & $199 / 386(51.6)$ & $122 / 156(78.2)$ & $147 / 165(89.1)$ \\
\hline \multicolumn{5}{|l|}{ Correlation between hand-drawn spiral rating (dominant } \\
\hline arm) and total tremor score ${ }^{3}$ & $0.66, \mathrm{p}<0.001$ & $0.70, \mathrm{p}<0.001$ & $0.73, p<0.001$ & $0.65, \mathrm{p}<0.001$ \\
\hline Answered 'yes' to the question, 'Does your hand usually & & & & \\
\hline tremor when you hold a pen or write your name?'1 & $43 / 106(40.6)$ & $304(78.8)$ & $135 / 159(84.9)$ & $159 / 176(90.3)$ \\
\hline $\begin{array}{l}\text { Values are proportions (percentage). In some cases, da } \\
{ }^{1} \text { The data in this row may be considered a measure of } \\
{ }^{2} \text { Tremor rating }=1.5 \text { was not assigned in this study pr } \\
{ }^{3} \text { Spearman's correlation coefficient, } p \text { value. }\end{array}$ & $\begin{array}{l}\text { a are missing. } \\
\text { ensitivity of the test. } \\
\text { tocol. }\end{array}$ & & & \\
\hline
\end{tabular}

Table 3. Severity of tremor in hand-drawn spirals in two control samples

\begin{tabular}{|c|c|c|}
\hline & $\begin{array}{l}\text { Population-based study in } \\
\text { northern Manhattan }\end{array}$ & $\begin{array}{l}\text { Study of the environmental } \\
\text { epidemiology of ET }\end{array}$ \\
\hline $\mathrm{n}$ & 268 & 429 \\
\hline$\geq 2$ in dominant $\operatorname{arm}^{1}$ & $8 / 268(3.0)$ & $0 / 429(0.0)$ \\
\hline$\geq 2$ in either $\operatorname{arm}^{1}$ & $18 / 268(6.7)$ & $0 / 429(0.0)$ \\
\hline$\geq 2$ in both arms ${ }^{1}$ & $1 / 268(0.4)$ & $0 / 429(0.0)$ \\
\hline$\geq 1.5$ in both arms ${ }^{1}$ & $\mathrm{NAv}^{2}$ & $4 / 429(0.9)$ \\
\hline \multicolumn{3}{|l|}{ Correlation between hand-drawn spiral rating (dominant arm) } \\
\hline and total tremor score ${ }^{3}$ & $0.45, \mathrm{p}<0.001$ & $0.52, \mathrm{p}<0.001$ \\
\hline \multirow{2}{*}{\multicolumn{3}{|c|}{$\begin{array}{l}\text { Answered 'yes' to the question, 'Does your hand usually tremor } \\
\text { when you hold a pen or write your name?' }\end{array}$}} \\
\hline & $10 / 268(3.7)$ & $5 / 429(1.2)$ \\
\hline \multicolumn{3}{|c|}{2 Tremor rating $=1.5$ was not assigned in this study protocol. } \\
\hline
\end{tabular}

The proportion of cases who answered 'yes' to the question 'Does your hand usually tremor when you hold a pen or write your name?' ranged from $40.6 \%$ (population-based study) to $90.3 \%$ (brain repository), with the number of such controls only being 1.2-3.7\% (table 2). Hence, as a screening tool, the question was less slightly sensitive than the presence of a rating $\geq 1.5$ on the handdrawn spiral in either arm (table 2).

\section{Discussion}

In the current study, the performance of the handdrawn spiral as a screening tool for ET depended somewhat on the sample of cases being studied and the cut-offs being employed for sensitivity and specificity. In general, the test was less sensitive in the population-based sample and less sensitive when the requirement was that a trem- 
or rating $\geq 2$ had to be present in both arms. Further lowering the requirement to a tremor rating that was $\geq 1.5$ (i.e., tremor that was of moderate amplitude and clearly oscillatory but only sometimes of moderate amplitude) in either arm increased the sensitivity without affecting specificity, with sensitivity ranging from $78.8-97.0 \%$ and specificity being $95.3 \%$ (i.e., $4.7 \%$ of controls had a spiral rating of this magnitude; table 2). The spiral correlated well with a global measure of tremor severity (i.e., the total tremor score) and it outperformed the screening question 'Does your hand usually tremor when you hold a pen or write your name?', although not by a large amount (table 2).

Despite its usage as a screening tool in ET, there are few published data on the validity of the hand-drawn spiral in ET. One cross-sectional study of several thousand people participating in a genetics study in Europe asked participants to draw one Archimedes spiral with the dominant arm [22]. The spiral was then rated using a $0-10$ point scale $[5,6]$. A positive screen was a score $>4$ [22], which is equivalent to a WHIGET rating of approximately 1.5-2. In that study, the spiral had a sensitivity of $52.6 \%$ and a specificity of $75.5 \%$ [22]. There are no other data.

Using the presented data, one may make several recommendations for investigators. A rating $\geq 1.5$ (tremor that was of moderate amplitude and clearly oscillatory but only sometimes of moderate amplitude) in either arm achieved a moderate-to-high sensitivity ranging from $78.8-97.0 \%$ and a high specificity of $95.3 \%$; this seemed to be the method that achieved the best results (table 2). A major caveat, which investigators should consider in their study design, is that the validity of the test varies depending on the cohort under study (table 2).

The test, while valid, did not perform much better than the screening question ('Does your hand usually tremor when you hold a pen or write your name?') in several settings, although in others (e.g., the population), the sensitivity of the screening question was only $40.6 \%$, whereas a hand-drawn spiral rating $\geq 2$ in either arm was noted in $69.8 \%$ of ET cases. Furthermore, the self-report of tremor often did not correctly identify those individuals who actually had tremor on examination. For example, in the study of the environmental epidemiology of ET, 25/82 (30.5\%) cases who answered 'no' to the screening question had a tremor rating $\geq 1.5$ in their dominant arm. Conversely, 38/304 (12.5\%) cases who answered 'yes' to the screening question had no or minimal tremor in their dominant arm (i.e., rating $\leq 0.5$ ).
These results should be interpreted in the context of the following limitation. The specificity of this test was assessed in the setting several large samples of control participants. It was not assessed in samples of Parkinson's disease or dystonia cases ascertained from a movement disorders clinic; hence, the utility of this test has not been tested in that specific context. This being said, the context that was assessed, in which the utility of this test was examined in population-based samples of normal controls, is of greatest interest for epidemiological studies. In such settings, the prevalence of both Parkinson's disease and dystonia is very low $(\leq 1.5 \%)$, so the more important distinction is between ET and normal controls [23-25]. Moreover, the need for a brief screening tool in the setting of a movement disorders clinic is negligible as one can perform a detailed examination on patients in that context.

The study had several strengths. First, an identical evaluation (i.e., the same task) was performed on nearly 1,500 persons. Tremor was rated using a reliable and valid rating scale by the same senior movement disorder neurologist; hence, there was no loss of precision due to poor inter-rater reliability. Third, these issues were assessed across four study settings in order to sample the broadest range of ET cases possible; in addition, in two of the studies, a control sample was enrolled.

In summary, the hand-drawn spiral is a sensitive and specific method of diagnosing ET. Furthermore, it serves as a valid measure of overall tremor severity.

\section{Acknowledgments}

This work was supported by NIH grants R01 NS039422, R01 NS042859, R01 NS073872 and UL1 TR000040. These research aims otherwise received no specific grant from any funding agency in the public, commercial or not-for-profit sectors.

\section{Disclosure Statement}

The author declares that there are no conflicts of interest and no competing financial interests.

\section{Contributions}

Elan D. Louis, MD, MSc: study conception and design, analysis and interpretation of data, study supervision, initial draft and critical revision of manuscript for important intellectual content. 


\section{References}

$>1$ Louis ED, Ferreira JJ: How common is the most common adult movement disorder? Update on the worldwide prevalence of essential tremor. Mov Disord 2010;25:534-541.

$>2$ Benito-Leon J, Bermejo-Pareja F, Morales JM, Vega S, Molina JA: Prevalence of essential tremor in three elderly populations of central Spain. Mov Disord 2003;18:389-394.

$\checkmark 3$ Dogu O, Sevim S, Camdeviren H, Sasmaz T, Bugdayci R, Aral M, et al: Prevalence of essential tremor: door-to-door neurologic exams in Mersin Province, Turkey. Neurology 2003;61:1804-1806.

4 Seijo-Martinez M, Del Rio MC, Alvarez JR, Prado RS, Salgado ET, Esquete JP, et al: Prevalence of essential tremor on Arosa Island, Spain: a community-based, door-to-door survey. Tremor Other Hyperkinet Mov (N Y) 2013;3:pii:tre-03-192-4299-1.

5 Bain P, Findley LJ: Assessing Tremor Severity. London, Smith-Gordon, 1993.

6 http://www.tremor.org.uk/publications. html.

$>7$ Louis ED, Zhao Q, Meng H, Ding D: Screening for action tremor in epidemiological field surveys: assessing the reliability of a semiquantitative, visual, template-based scale for rating hand-drawn spirals. Tremor Other HyperkinetMov(NY)2012;2:pii:tre-02-46-177-2.

$>8$ Louis ED, Ford B, Wendt KJ, Cameron G: Clinical characteristics of essential tremor: data from a community-based study. Mov Disord 1998;13:803-808.

>9 Dogu O, Louis ED, Sevim S, Kaleagasi H, Aral M: Clinical characteristics of essential tremor in Mersin, Turkey - a population-based doorto-door study. J Neurol 2005;252:570-574.
10 Louis ED, Ford B, Frucht S: Factors associated with increased risk of head tremor in essential tremor: a community-based study in northern Manhattan. Mov Disord 2003;18:432436.

11 Louis ED, Zheng W, Applegate L, Shi L, Factor-Litvak P: Blood harmane concentrations and dietary protein consumption in essential tremor. Neurology 2005;65:391-396.

12 Louis ED, Hernandez N, Ionita-Laza I, Ottman R, Clark LN: Does rate of progression run in essential tremor families? Slower vs. faster progressors. Parkinsonism Relat Disord 2013;19:363-366.

13 Louis ED, Borden S, Moskowitz CB: Essential tremor centralized brain repository: diagnostic validity and clinical characteristics of a highly selected group of essential tremor cases. Mov Disord 2005;20:1361-1365.

14 Louis ED, Rios E, Applegate LM, Hernandez NC, Andrews HF: Jaw tremor: prevalence and clinical correlates in three essential tremor case samples. Mov Disord 2006;21:18721878 .

15 Louis ED, Ottman R, Ford B, Pullman S, Martinez M, Fahn S, et al: The Washington heights-inwood genetic study of essential tremor: methodologic issues in essentialtremor research. Neuroepidemiology 1997; 16:124-133.

16 Louis ED, Ottman R, Clark LN: Clinical classification of borderline cases in the family study of essential tremor: an analysis of phenotypic features. Tremor Other Hyperkinet Mov (N Y) 2014;4:220.

17 Louis ED, Hernandez N, Rabinowitz D, Ottman R, Clark LN: Predicting age of onset in familial essential tremor: how much does age of onset run in families? Neuroepidemiology 2013;40:269-273.
18 Babij R, Lee M, Cortes E, Vonsattel JP, Faust PL, Louis ED: Purkinje cell axonal anatomy: quantifying morphometric changes in essential tremor versus control brains. Brain 2013; 136:3051-3061.

19 Louis ED, Ford B, Bismuth B: Reliability between two observers using a protocol for diagnosing essential tremor. Mov Disord 1998; 13:287-293.

20 Louis ED, Wendt KJ, Albert SM, Pullman SL, Yu Q, Andrews H: Validity of a performancebased test of function in essential tremor. Arch Neurol 1999;56:841-846.

-21 Louis ED, Pullman SL: Comparison of clinical vs. electrophysiological methods of diagnosing of essential tremor. Mov Disord 2001;16: 668-673.

22 Lorenz D, Papengut F, Frederiksen H, Kopper F, Klebe S, Christensen K, et al: Evaluation of a screening instrument for essential tremor. Mov Disord 2008;23:1006-1012.

23 Benito-Leon J, Bermejo-Pareja F, Rodriguez J, Molina JA, Gabriel R, Morales JM: Prevalence of PD and other types of parkinsonism in three elderly populations of central Spain. Mov Disord 2003;18:267-274.

24 Defazio G, Abbruzzese G, Livrea P, Berardelli A: Epidemiology of primary dystonia. Lancet Neurol 2004;3:673-678.

25 Papantonio AM, Beghi E, Fogli D, Zarrelli M, Logroscino G, Bentivoglio A, et al: Prevalence of primary focal or segmental dystonia in adults in the district of foggia, southern Italy: a service-based study. Neuroepidemiology 2009;33:117-123. 